\title{
Day Times Microgram Per Milliliter Per Kilogram
}

National Cancer Institute

\section{Source}

National Cancer Institute. Day Times Microgram Per Milliliter Per Kilogram. NCI

Thesaurus. Code C112249.

Days times micrograms per milliliter, divided by kilograms. 